\title{
Histopathological Study of Endometrial Biopsy Specimens for Abnormal Uterine Bleeding
}

\author{
Archana Tiwari, ,a,d Narinder Kaur, ${ }^{\text {a,e }}$ Sushila Jain, ${ }^{\mathrm{b}, \mathrm{e}}$ Ramji Rai, ${ }^{\mathrm{c}, \mathrm{d}}$ \\ Surendra Kumar Jain ${ }^{c, d}$
}

\begin{abstract}
:
Introduction: Endometrial specimen for abnormal uterine bleeding (AUB) is the one of the commonest specimens received in histopathology laboratory. Histopathological characteristics of endometrial tissues, as assessed by light microscopy, remains the diagnostic standard for the management of AUB. The objective of study is to find out the histopathological pattern of endometrium in AUB in the light of clinical details. Methods: This was a prospective observational study carried out in the department of Pathology, Lumbini Medical College Teaching Hospital for a period of two years from June 2014 to May 2016. Formalin fixed endometrial specimens were processed, paraffin embedded, sectioned at 3-4 $\mu \mathrm{m}$, stained with hematoxylin and eosin, and studied under light microscopy along with their demographics. Data were collected, entered and analyzed using SPSS version 20. Results: The study included 100 cases of endometrial biopsy specimens with clinical diagnosis of AUB. Menstrual disturbances was found in wide age range between 17-75 years with the mean age of $45(S D=13.36)$ years. Menorrhagia was the commonest $(n=60,60 \%)$ clinical presentation. Most ( $n=85 ; 85 \%$ ) endometrium had non-neoplastic lesions. Among them, normal endometrial patterns were commonest ( $n=50,50 \%)$. Neoplastic lesions $(n=15,15 \%)$ were distributed in all menstruation status with majority in postmenopause $(n=7,7 \%)$ and included malignant cases $(n=5,5 \%)$ among others. Conclusion: Postmenopausal bleeding was common presentation among women with malignant and premalignant disease which was present in $15 \%$ of the cases together. Timely evaluation of AUB by histopathology can be life saving with early tissue diagnosis and management.
\end{abstract}

Keywords: biopsy • endometrium • histology • uterine hemorrhage $\bullet$ uterine neoplasm

\section{INTRODUCTION:}

Endometrial samples are among most common specimens in day-to-day surgical

a - Lecturer

b - Assistant Professor

c - Professor

d - Department of Pathology, Lumbini Medical College (LMC), Nepal

e - Department of Obstetric and Gynecology, LMC, Nepal

Corresponding Author:

Dr. Archana Tiwari

e-mail: archana445@gmail.com

How to cite this article:

Tiwari A, Kaur N, Jain S, Rai R, Jain SK. Histopathological study of endometrial biopsy specimens for abnormal uterine bleeding. Journal of Lumbini Medical College. 2016;4(2):72-6. doi: 10.22502/jlmc. v4i2.94. pathology practice accounting for major proportion of workload and present a unique challenge for the surgical pathologist. ${ }^{1}$ The endometrium undergoes a plethora of changes, by the complex interplay of endogenous sex steroids and other systemic as well as iatrogenic factors. ${ }^{2}$ The most common indication for endometrial sampling is the workup of abnormal uterine bleeding (AUB). ${ }^{1}$ AUB is a new terminology that describes both dysfunctional uterine bleeding and bleeding from structural causes. ${ }^{3,4}$ In women of childbearing age, abnormal uterine bleeding includes any change in menstrual-period frequency or duration, or amount of flow, and bleeding between cycles. Patterns of abnormal endometrial bleeding include menorrhagia, metrorrhagia, and menometrorrhagia as well as postmenopausal bleeding (PMB). ${ }^{4}$ 
The spectrum of AUB affects up to a third of women of child bearing age and may be a reflection of serious underlying pathology. Menorrhagia affects $10-30 \%$ of menstruating women at any one time, and may occur at sometime during peri-menopause in up to $50 \%$ of women. ${ }^{5}$

Nearly $40 \%$ of premenopausal women with endometrial carcinoma will present with menorrhagia as their only complaint. AUB in the form of PMB is an important symptom not to be underestimated. It is an alarming symptom that indicates malignancy until proved otherwise and therefore, requires prompt histopathological evaluation to eliminate possibility of malignancy. ${ }^{6,7}$

Endometrial abnormalities are common diagnostic challenges faced by the pathologist and referring gynecologist. Representative endometrial specimens can be received following varieties of correctly timed endometrial sampling techniques including curettage, biopsies, and aspiration. ${ }^{8,9}$ As the regular endometrial cycle follows a precisely scheduled series of morphological changes, there are wide range of diagnostic possibilities in the evaluation of women who present with AUB. ${ }^{1,5,6}$ In most cases, non- neoplastic conditions are identified as cause for AUB such as normal endometrium, other than normal endometrium, and inflammatory endometrium. ${ }^{1}$ However, endometrial carcinoma is one of the most common malignancy of the female genital tract and is often preceded by a histologically evident precursor lesion, "hyperplasias". The pathologist is expected to exclude an endometrial cancer or precancerous lesion; although a malignancy is found in $10-15 \%$ of the cases. ${ }^{1,10}$

Significant morbidity or mortality can occur if endometrial hyperplasia is untreated with progression to malignancy. ${ }^{10,11}$ In the original study by Kurman et al., cited by Chiang JW., simple hyperplasia was associated with a $1 \%$ rate of progression to cancer, $3 \%$ rate of progression to complex hyperplasia, and $8 \%$ rate of progression to simple atypical hyperplasia, whereas complex atypical hyperplasia had a $29 \%$ rate of progression to cancer. ${ }^{12}$

While the detailed clinical examination and imaging studies can attempt to determine the site of bleeding and its source, the goals of clinical management are primarily dependent upon attaining a histopathological diagnosis and classification of lesion.

This study demonstrates the spectrum of normal and pathologic findings in endometrial biopsy specimens in women of all menstrual status.

\section{METHODS:}

This was an observational prospective study, carried out at department of pathology, Lumbini Medical College Teaching Hospital for two years duration from June 2014 to May 2016. All endometrial specimens submitted to department of pathology with the clinical diagnosis of AUB for histopathological examination were included in the study.

Inadequate samples, follow up cases of endometrial malignancies, gravid patients, postoperative, postpartum, and pregnancy-related bleedings were excluded.

Endometrial tissues were fixed in 10\% formalin and processed. The paraffin embedded tissues were sectioned at 3-4 $\mu \mathrm{m}$ and then stained with hematoxylin and eosin stain. Sections were studied by pathologists under light microscopy along with patient's clinical details.

\section{RESULTS:}

Total number of surgical pathologic specimens received during two years of the study period was 2905. Among them, endometrial samples accounted for 150 (5.2\%) specimens including 115 (4\%) samples for AUB. Sections from 15 specimens were inadequate for evaluation. Thus, a total of 100 cases were evaluated from the histopathological specimens submitted with the diagnosis of AUB.

Menstrual disturbances were found in wide age range between 17-75 years. The mean age was $45(S D=13.4)$ years. Menorrhagia was the commonest $(n=60,60 \%)$ clinical presentation while post-menopausal bleeding was the most common $(n=7,7 \%)$ clinical presentation among cases with premalignant and malignant endometrial patterns.

Duration of presenting complaints ranged from one month to 10 years. Most $(n=65,65 \%)$ of the patients had symptoms for less than six months duration and majority ( $n=88,88 \%)$ were multiparous. Eighty-five (85\%) cases had non-neoplastic lesions.

Among non-neoplastic cases, normal endometrial patterns were the commonest $(n=50$, $50 \%$ ). Details of the histopathological pattern of non-neoplastic lesions is shown in Table 1.

Five cases (5\%) harbored malignant pathology while nine cases $(9 \%)$ had premalignant and one had benign polyp (Table 2). Simple hyperplasia without atypia was predominant in premenopausal status while complex hyperplasia with atypia was noted in post-menopause. Malignant 
endometrial lesions were equally distributed in all menstruation status (Table 3).

Table 1. Histopathological pattern of non-neoplastic lesions.

\begin{tabular}{|c|c|c|c|c|}
\hline \multicolumn{2}{|c|}{$\begin{array}{l}\text { Non-neoplastic } \\
\text { endometrial lesions }\end{array}$} & $\begin{array}{l}\text { Histopathological } \\
\text { diagnosis }\end{array}$ & $n(\%)$ & $\begin{array}{c}n \\
(\%)\end{array}$ \\
\hline \multirow{4}{*}{\multicolumn{2}{|c|}{$\begin{array}{l}\text { Normal endometrial } \\
\text { patterns. }\end{array}$}} & Proliferative phase & $30(30)$ & \multirow{4}{*}{$\begin{array}{c}50 \\
(50)\end{array}$} \\
\hline & & Secretory phase & $14(14)$ & \\
\hline & & $\begin{array}{l}\text { Atrophic (Post } \\
\text { menopausal) }\end{array}$ & $3(3)$ & \\
\hline & & $\begin{array}{l}\text { Weakly proliferative } \\
\text { (Post menopausal) }\end{array}$ & $3(3)$ & \\
\hline \multirow{5}{*}{ 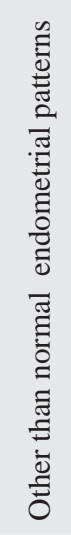 } & $\begin{array}{l}\text { Non-secretory } \\
\text { endometrium }\end{array}$ & $\begin{array}{l}\text { Disordered } \\
\text { Proliferative } \\
\text { Endometrium }\end{array}$ & $12(12)$ & \multirow{5}{*}{$\begin{array}{c}20 \\
(20)\end{array}$} \\
\hline & \multirow{2}{*}{$\begin{array}{l}\text { Secretory } \\
\text { patterns }\end{array}$} & $\begin{array}{l}\text { Out of phase Secre- } \\
\text { tory endometrium }\end{array}$ & $1(1)$ & \\
\hline & & $\begin{array}{l}\text { Dyssynchronously } \\
\text { developed Secretory } \\
\text { Endometrium }\end{array}$ & $1(1)$ & \\
\hline & \multirow{2}{*}{$\begin{array}{l}\text { Gestational } \\
\text { pattern }\end{array}$} & $\begin{array}{l}\text { Gestational pattern } \\
\text { without placental } \\
\text { tissue/fetal parts }\end{array}$ & $3(3)$ & \\
\hline & & $\begin{array}{l}\text { Retained bits of } \\
\text { POC }\end{array}$ & $3(3)$ & \\
\hline \multirow{3}{*}{\multicolumn{2}{|c|}{ Inflammatory pattern }} & $\begin{array}{l}\text { Chronic Nonspecific } \\
\text { endometritis }\end{array}$ & $10(10)$ & \multirow{3}{*}{$\begin{array}{c}15 \\
(15)\end{array}$} \\
\hline & & $\begin{array}{l}\text { Acute endometritis/ } \\
\text { Pyometra }\end{array}$ & $2(2)$ & \\
\hline & & $\begin{array}{l}\text { Granulomatous } \\
\text { endometritis }\end{array}$ & $3(3)$ & \\
\hline \multicolumn{3}{|c|}{ Total } & \multicolumn{2}{|c|}{$85(85)$} \\
\hline
\end{tabular}

Table 2. Histopathological patterns in Neoplastic lesions

\begin{tabular}{ccc}
\hline Neoplastic lesions & Histopathology & $\mathbf{n ( \% )}$ \\
\hline Benign lesions & $\begin{array}{l}\text { Endometrial polyp } \\
\text { Simple hyperplasia }\end{array}$ & $1(1)$ \\
& $\begin{array}{l}\text { without atypia } \\
\text { Simple hyperplasia }\end{array}$ & $1(1)$ \\
$\begin{array}{l}\text { Pre-malignant } \\
\text { lesions }\end{array}$ & $\begin{array}{l}\text { with atypia } \\
\text { Complex hyperplasia } \\
\text { without atypia }\end{array}$ & $2(2)$ \\
\hline $\begin{array}{l}\text { Complex hyperplasia } \\
\text { Lalignant }\end{array}$ & $\begin{array}{l}\text { Endometrioid } \\
\text { adenocarcinoma }\end{array}$ & $4(4)$ \\
\hline Total & Clear cell carcinoma & $1(1)$ \\
\hline
\end{tabular}

\section{DISCUSSION:}

The main objective of endometrial curettage in excessiveuterinebleeding to exclude the possibility of local intrauterine lesion such as incomplete abortion, uterine polyps, endometritis, and carcinoma as a cause of bleeding. ${ }^{1}$ Out of 100 cases, 85 (85\%) cases had non-neoplastic lesions and 15 (15\%) cases had neoplastic and related endometrial lesions. The leading lesions besides normal endometrium were other than normal endometrial patterns, seen in 20 (20\%) cases. Disordered proliferative endometrium was the most common (12\%) other than normal endometrial patterns which is much lower than the findings by Maksem et al. (26.9\%) and Sarfraz et al. (41\%). ${ }^{13,14}$ Inflammatory patterns were found in 15 (15\%) cases which is much lesser than $30 \%$ seen in a study by Maksem et al. but higher than $2.5 \%$ in that by Baral et al. ${ }^{13,15}$ Chronic non-specific endometritis accounted for 10 (10\%) cases which was higher than study done in India (1.8\%) and Nigeria (1.36\%). ${ }^{16,17}$ The cases of tuberculous endometritis (3\%) are not so high as in other organs in our place, however, was higher than $0.15 \%$ of total endometrial biopsies in a study done by Jha et al. in TUTH, Nepal. ${ }^{18}$ Similarly, our figures are higher than in a study by Mani et al. in which tuberculous endometritis based on histology was detected in two cases (1.8\%). ${ }^{16}$ In contrast, it is much lower than $24.5 \%$ in one study done in India. ${ }^{19}$ There were three cases of retained bits of product of conception (POC) in this study with the past history of abortion five months, nine months and 12 months back respectively. Sahinoglu et al. reported an unusual case of postmenopausal uterine bleeding due to prolonged retention of fetal bones after a mid trimester abortion 17 years back. ${ }^{20}$

The prevalence of endometrial polyp in the general population is about $24 \% .^{21}$ In this study, endometrial polyp was least common (1\%) among neoplastic and related lesions which is much lower as compared to $10 \%$ in study by Aslam et al. but similar to $1.3 \%$ in the study by Baral et al..$^{15,22}$ Polyp manifested as AUB in $45.6 \%$ of study population in the study of Kanthi et al. which is surprisingly high in comparison to our findings and are probably due

Table 3: Distribution of endometrial pathology according to menstruation status

\begin{tabular}{cccccc}
\hline Menstrual status & Non-neoplastic $(\boldsymbol{n})$ & Benign (Polyp, $\boldsymbol{n})$ & Premalignant $(\boldsymbol{n})$ & Malignancy $(\boldsymbol{n})$ & $\boldsymbol{n}$ \\
\hline Pre-menopause & 55 & 1 & 3 & 1 & 60 \\
Peri-menopause & 20 & 0 & 1 & 5 & 2 \\
Post-menopause & 10 & 0 & $\mathbf{9}$ & $\mathbf{5}$ & 17 \\
\hline Total & $\mathbf{8 5}$ & $\mathbf{1}$ & & $\mathbf{1 0 0}$ \\
\hline
\end{tabular}


to difference in patient selection. ${ }^{23}$

Premalignant lesions were discovered in nine (9\%) cases which were lesser than $18.3 \%$ in a study by Baral et al. ${ }^{15}$ Complex hyperplasia with atypia was the most common (4\%) form of endometrial hyperplasia which was higher than $1.3 \%$ in studies by Takreem et al. and in Tabata et al. ${ }^{24,25}$

The frequency of endometrial carcinoma in our study was $5 \%$ of total endometrial biopsies and it was higher compared to a study done in Nepal by Dhakal et al. (2\%, $N=32)$ and Aslam et al. (1\%). ${ }^{26,22}$ In contrast to present study, in a study of 1837 patients aged over 26 years in Japan, 2.8\% patients were found to have malignant disease, of which, $2.6 \%$ of patients had endometrial carcinoma and $0.2 \%$ had other malignancies. ${ }^{25}$ Another study by Dangal in chitwan valley, Nepal, also showed higher frequency of endometrial malignancies (16.6\%) while study by Baral et al. in Kathmandu valley showed $21 \%$ cases of endometrial carcinoma, all in post menopausal age group. ${ }^{27,15}$ Endometrioid adenocarcinoma was predominant histological type ( $n=4,80 \%$ of total malignancies) which was similar to other studies. ${ }^{15,22,26,27}$

Sixty percent of women in present study presenting with AUB were in their premenopausal status and only 17 cases (17\%) presented with postmenopausal bleeding. In contrast to this, Dangal et al. showed premenopausal bleeding in $43 \%$ and

\section{REFERENCES:}

1. Longacre TA, Atkins KA, Kempson RL, Hendrickson MR. The uterine corpus. $5^{\text {th }}$ ed. Mills SE, editor. Sternberg's Diagnostic surgical pathology. Philadelphia: Lippincott Williams and Wilkins; 2010. 2184-2277 p.

2. Crum CP, Hornstein MD, Nucci MR, Mutter GI. Hertig and beyond: a systematic and practical approach to the endometrial biopsy. Adv Anat Pathol. 2003 Nov;10(6):30118.

3. Confino E. Abnormal uterine bleeding, a new terminology is needed. Fertility and Sterility. 2007; 87(3):479-80.

4. Fraser IS, Critchley HO, Munro MG. Abnormal uterine bleeding: getting our terminology straight. Curr Opin Obstet Gynecol. 2007 Dec;19(6):591-5.

5. Padubidri VG, Daftary SN. Menorrhagia and Dysfunctional uterine bleeding (DUB). $13^{\text {th }}$ ed. Padubidri VG, Daftary $\mathrm{SN}$, editors. Shaw's text book of gynaecology. Elsevier; 2004. 291-9 p.

6. Dutta DC. Abnormal Menstrual bleeding. $4^{\text {th }}$ ed. Konar H, editor. Text book of gynaecology including contraception. New central book agency (P) Ltd; 2003. 175-86 p. postmenopausal bleeding in 34\%. ${ }^{27}$ Hunter et al. also showed predominance of post menopausal bleeding in their study (41.8\%). ${ }^{28}$ Causes of postmenopausal bleeding included endometrial atrophy (75\%), endometrial polyps, endometrial hyperplasia, endometrial carcinoma (10\%), and estrogen withdrawal. ${ }^{1,5-7,29}$. In our study most common pathology in PMB was endometrial hyperplasia (5\%) following non-neoplastic other than normal endometrial patterns (10\%). Endometrial carcinoma in PMB accounted for $2 \%$ of total cases. Dangal et al. showed the much higher incidence $(17.6 \%)$ of endometrial cancer in the postmenopausal group. ${ }^{27}$ For women with postmenopausal bleeding, the incidence of endometrial cancer ranges from $4.9 \%$ to $11.5 \%{ }^{29}$

\section{CONCLUSION:}

Abnormal uterine bleeding (AUB) is a common gynaeco-pathological problem with varied clinical presentation and multiple causes. Endometrium specimens form a significant proportion of workload of histopathology laboratory in our institute. Post-menopausal bleeding was common presentation among women with malignant and premalignant disease which was present in 15\% of the cases together. Timely evaluation of AUB by histopathology can be life saving with early tissue diagnosis and management.
7. Wagman H. Post-menopausal bleeding. Baillieres Clin Obstet Gynaecol. 1988 Jun;2(2):355-62.

8. Demirkiran F, Yavuz E, Erenel H, Bese T, Arvas M, Sanioglu C. Which is the best technique for endometrial sampling? Aspiration (pipelle) versus dilatation and curettage (D\&C). Arch Gynecol Obstet. 2012 Nov;286(5):1277-82.

9. Reddington L, Hernandez E, Balsara G, Hughes D, Anderson L, Heller PB. The effectiveness of the Masterson curette in sampling the endometrial cavity. J Nati Med Assoc. 1995;87:877-80.

10. Clark TJ, Mann CH, Shah N, Khan KS, Song F, Gupta JK. Accuracy of outpatient endometrial biopsy in the diagnosis of endometrial cancer: a systematic quantitative review. BJOG. 2002 Mar;109(3):313-21.

11. Balcano JS. Investigating the endometrium - a clinical point of view. Heller DS, editor. The endometrium: A clinicopathologic approach. New York: Igaku-shoin; 1994. 3-8 p.

12. Chiang JW, Wilcox N. Premalignant Lesions of the Endometrium. WebMD professional. 2011. 
13. Maksem JA, Meiers I, Robboy SJ. A primer of endometrial cytology with histological correlation. Diagnostic Cytopathology. 2007;35(12):817-44.

14. Sarfraz R, Ahmed MM, Tahir TM, Ahmed MS. Benign lesions in abdominal hysterectomies in women presenting with menorrhagia. Biomedica. 2011 Jan-Jun;27(17):72-5.

15. Baral R, Pudasaini S. Histopathological pattern of endometrial samples in abnormal uterine bleeding. Journal of Pathology of Nepal. 2011;1(1):13-6.

16. Mani R, Nayak S, Kagal A, Bharadwaj R. Tuberculous endometritis in infertility: a bacteriological and histopathological study. Ind J Tub. 2003;50:161.

17. Ojo BA, Aboyeji PA, Buhari MO, Abdulraman MB. Endometrial pathology in a teaching hospital in North Central Nigeria: a histopathological survey. Nigerian Journal of Health and Biomedical Sciences. 2005;4(2):10711.

18. Jha A, Sayami G, Adhikari R, Jha R. Female genital tract tuberculosis in Tribhuvan University Teaching Hospital: A retrospective one year histopathological study. N J Obstet Gynaecol. 2007;2(2):29-34.

19. Reys, Maheshwari HB. Tuberculosis of the endometrium: A histopathological study of 500 biopsy cases. Ind J Tub. 1971;18:27-33.

20. Sahinoglu Z, Kuyumcuoglu U. An unusual case of postmenopausal vaginal bleeding: retention of fetal bone. Arch Gynaecol. 2003;267(3):160-2.

21. Mutter GL, Ince TA. Tumors of the female genital tract: Endometrium. $3^{\text {rd }}$ ed. Fletcher CDM, editor. Diagnostic Histopathology of tumors. Edinburgh: Churchill Livingstone; 2007. 652-71 p.
22. Aslam M, Ijaz L,Tariq S, Shafqat K, Meher-un-Nisa, Ashraf $\mathrm{R}$, et al. Comparison of Transvaginal sonography and saline contrast sonohysterography in women with abnormal uterine bleeding: correlation with hysteroscopy and histopathology. Int J Health Sci (Qassim). 2007 Jan;1(1):17-24.

23. Kanthi JM, Remadevi C, Sumathy S, Sharma D, Sreedhar S, Jose A. Clinical Study of Endometrial Polyp and Role of Diagnostic Hysteroscopy and Blind Avulsion of Polyp. J Clin Diagn Res. 2016 Jun;10(6):QC01-4.

24. Takreem A, Danish N, Razaq S. Incidence of endometrial hyperplasia in 100 cases presenting with polymenorrhagia/ menorrhagia in perimenupausal women. J Ayub Med Coll Abbottabad. 2009 Apr-Jun;21(2):60-3.

25. Tabata T, Yamawaki T, Ida M, Nishimura K, Nose Y, Yabana T. Clinical value of dilatation and curettage for abnormal uterine bleeding. Arch Gynaecol Obstet. 2001;264:174-6.

26. Dhakal HP, Pradhan M. Histological pattern of gynecological cancers. JNMA J Nepal Med Assoc. 2009;48:301-5.

27. Dangal G. Endometrial study of abnormal uterine bleeding in women at 45 years and above. JNMA J Nepal Med Assoc. 2003;42:83-5.

28. Hunter DC, McClure N. Abnormal uterine bleeding: an evaluation endometrial biopsy, vaginal ultrasound and outpatient hysteroscopy. Ulster Med J. 2001 May;70(1):2530 .

29. Munro MG. Investigation of Women with Postmenopausal Uterine Bleeding: Clinical Practice Recommendations. Perm J. 2014 Winter;18(1):55-70. 